\title{
Is there a trend in cirrus cloud cover due to aircraft traffic?
}

\author{
F. Stordal ${ }^{1,2}$, G. Myhre ${ }^{1,2}$, E. J. G. Stordal ${ }^{2}$, W. B. Rossow $^{3}$, D. S. Lee ${ }^{4}$, D. W. Arlander ${ }^{2,}{ }^{*}$, and T. Svendby ${ }^{2}$ \\ ${ }^{1}$ Department of Geosciences, University of Oslo, Norway \\ ${ }^{2}$ Norwegian Institute for Air Research, Kjeller, Norway \\ ${ }^{3}$ NASA/Goddard Institute for Space Studies, New York, New York, USA \\ ${ }^{4}$ Department of Environment and Geographical Sciences, Manchester Metropolitan University, UK \\ *now at: Bureau of Patents, Oslo, Norway
}

Received: 20 September 2004 - Published in Atmos. Chem. Phys. Discuss.: 13 October 2004

Revised: 23 June 2005 - Accepted: 12 July 2005 - Published: 11 August 2005

\begin{abstract}
Trends in cirrus cloud cover have been estimated based on 16 years of data from ISCCP (International Satellite Cloud Climatology Project). The results have been spatially correlated with aircraft density data to determine the changes in cirrus cloud cover due to aircraft traffic. The correlations are only moderate, as many other factors have also contributed to changes in cirrus. Still we regard the results to be indicative of an impact of aircraft on cirrus amount. The main emphasis of our study is on the area covered by the METEOSAT satellite to avoid trends in the ISCCP data resulting from changing satellite viewing geometry. In Europe, which is within the METEOSAT region, we find indications of a trend of about $1-2 \%$ cloud cover per decade due to aircraft, in reasonable agreement with previous studies. The positive trend in cirrus in areas of high aircraft traffic contrasts with a general negative trend in cirrus. Extrapolation in time to cover the entire period of aircraft operations and in space to cover the global scale yields a mean estimate of $0.03 \mathrm{Wm}^{-2}$ (lower limit 0.01 , upper limit $0.08 \mathrm{Wm}^{-2}$ ) for the radiative forcing due to aircraft induced cirrus. The mean is close to the value given by IPCC (1999) as an upper limit.
\end{abstract}

\section{Introduction}

Condensation trails (contrails) from jet aircraft are visible in many industrialized regions and constitute one of several mechanisms that could influence the Earth's radiative balance. Contrails can often disappear quickly, but sometimes they persist for longer time periods and even evolve into cirrus clouds. Minnis et al. (1998) used information from a geostationary satellite to follow three events where contrails were converted into cirrus clouds. These contrail systems lasted up to $17 \mathrm{~h}$. Duda et al. (2004) used a combination

Correspondence to: F. Stordal

(frode.stordal@geo.uio.no) of flight data, meteorological data and satellite remote sensing to study development of contrails over the Great Lakes, demonstrating the formation of aircraft contrails with subsequent spreading. From surface observations it would be difficult to distinguish cirrus clouds evolving from contrails from natural cirrus. Although the possibility of contrails evolving into cirrus clouds was pointed out several years ago (Machta and Carpenter, 1971; Changnon, 1981), the extent of such cirrus clouds and their climate effect remain highly uncertain.

Boucher (1999) used synoptic cloud reports from land and ship stations to derive trends of cirrus clouds and further related these trends to fossil fuel consumption by aircraft traffic. He found an increase in the occurrence of cirrus clouds that could be related to aircraft traffic. Over the continental regions with the most aircraft traffic he determined the trend in cirrus to be almost as large as $3 \%$ cloud cover over a 10-year period, after correcting for a negative trend in cirrus "amount when present". Zerefos et al. (2003) analyzed trends in cirrus cloud cover based on data from ISCCP (International Satellite Cloud Climatology Project). After removing variations associated with ENSO, QBO and NAO they found a trend in cirrus cloud cover over northern midlatitudes, which, to a large extent, paralleled increases in fuel consumption by aircraft, leading to their conclusion that there is evidence of a possible aviation effect on cirrus cloud cover. Minnis et al. (2004) analysed surface observations of clouds and cloud data from ISCCP in combination with upper tropospheric humidity (from National Centers for Environmental Prediction, NCEP), finding that positive trends in cirrus in certain regions were most likely due to air traffic (e.g. the US).

Aircraft induced contrails and cirrus clouds impact longwave and shortwave radiation, with a general predominance of the longwave effect. Such clouds, like naturally occurring cirrus clouds, therefore have a net positive radiative effect (e.g. Chen et al., 2000). In IPCC $(1999,2001)$ a global mean

(C) 2005 Author(s). This work is licensed under a Creative Commons License. 
radiative forcing caused by contrails and aircraft induced cirrus was estimated to be 0.02 and 0.04 (upper limit) $\mathrm{Wm}^{-2}$, respectively. The IPCC forcing for cirrus is very uncertain, thus a best estimate was not recommended. Although the global mean of these forcings are small, the regional radiative forcing may be more significant. In Europe and North America the forcing due to contrails may reach $0.5 \mathrm{Wm}^{-2}$ (Minnis et al., 1999; Myhre and Stordal, 2001).

Travis et al. (2002) found a significant increase in the diurnal temperature range over the USA during the 3 days following 11 September 2001 when all commercial aircraft traffic was grounded. Contrails and aircraft induced cirrus clouds affect the diurnal temperature because during the night their longwave effect inhibits cooling. On the other hand, during the day the longwave effect and shortwave effects are rather similar but opposite in sign: the shortwave effect could even dominate and yield a cooling (Myhre and Stordal, 2001; Ponater et al., 2002). The Travis et al. (2002) study showed a larger than 1 degree increase in the diurnal temperature range compared to the three day periods before and after the grounding of the aircraft traffic. This is clearly larger than what would be expected from contrails alone, pointing towards cirrus clouds evolving from contrails as a potentially significant effect in affecting the diurnal temperature range.

The present study is based on satellite observations of cirrus and seeks to identify trends that can possibly be related to aircraft traffic. In our study we use ISCCP data over a 16 year period. Although we take a global approach we focus on the region viewed by METEOSAT, where spurious contributions to trends in cirrus due to variations in satellite viewing geometry are minimal.

\section{Data and analysis method}

\subsection{ISCCP data}

The ISCCP project was established in the early 1980s. One of the aims was to produce global calibrated and normalized radiance dataset for the infrared (IR) and visible (VIS) from which cloud parameters could be derived. The ISCCP cloud analysis procedure contains three principal parts: cloud detection, radiative model analysis, and statistical analysis (Rossow and Schiffer, 1991; Rossow and Garder, 1993). Although there are several factors introducing uncertainties in the ISCCP data, the long and continuous data record makes it one of the best products in studies of long term trends in cirrus clouds.

The primary data products of ISCCP are a collection of VIS and IR radiation images from the operational constellation of weather satellites that have been normalized to a standard reference calibration (Schiffer and Rossow, 1985). Data are taken from the geostationary satellites METOSAT (Meteorological Satellite), GMS (Geostationary Meteorological Satellite), GOES (Geostationary Operational Environmental
Satellite) East and West, as well as from polar NOAA (National Oceanographic and Atmospheric Administration) A (Afternoon) and M (Morning) orbiters.

In the ISCCP cloud detection procedure each individual satellite pixel $(4-7 \mathrm{~km})$ is classified as cloudy or clear (Rossow and Garder, 1993). To be classified as cloudy, either the VIS or the IR radiance must differ from its corresponding clear sky value by more than a pre-defined detection threshold. Each pixel is assumed to be completely cloudy or cloud free according to this criterion. Fractional cloud cover is only estimated for larger areas, according to the fractional number of pixels containing clouds. In our analysis we have used the monthly mean D2 data product (Rossow and Schiffer, 1999) on a $2.5^{\circ}$ equal area grid for the 16 year period 1984-1999.

We use the ISCCP datasets for cirrus clouds in an attempt to study the formation of cirrus from aircraft contrails. The dataset is derived from a combination of visible and IR information (denoted as ISCCP VIS/IR), with results only during the day. The VIS radiances are used to determine the optical thickness, which is a basis for a correction of the cloud top temperature, resulting in a better classification of thin cirrus clouds.

High clouds (ISCCP VIS/IR) have been compared (see Rossow and Schiffer, 1999) to SAGE (Stratospheric Aerosol and Gas Experiments) data (Liao et al., 1995) and two different analyses of HIRS (High-Resolution Infrared Sounder; Jin et al., 1996; Stubenrauch et al., 1999). In summary, those comparisons showed that the ISCCP VIS/IR high cloud amounts are lower than the other datasets by at least $0.05-$ 0.10. The discrepancies include uncertainties in all the datasets but are consistent with the lower detection sensitivity of ISCCP, which limits it to clouds with optical depths $>0.3$. Nevertheless these studies also show that the geographic and time variations of the cirrus in these datasets are well correlated. Although ISCCP does not recognize cirrus over other clouds, these cirrus have less radiative effect due to the cold and bright underlaying surfaces. Thus, although ISCCP may underestimate the total amount of cirrus change, this has little effect on the radiative forcing.

In Fig. 1 we show a global map of the average amounts of cirrus for the 1984-1999 period. The well known features of large cloud amounts are seen in the tropics (over South America, Africa and Indonesia). One particular feature in the distribution shown in Fig. 1 must be noted, namely the fact that there are discontinuities in the data at the borders between areas covered by different satellites. One example is the Indian Ocean, which is covered by three satellite instruments, namely the geostationary GMS east of the southern tip of India and METEOSAT west of the south-eastern tip of the Arabian peninsula, as well as the polar orbiter NOAA-A in between. This pattern is a result of the use of a constant radiance threshold for cloud detection that has been set to be sensitive enough to detect very thin cirrus (Rossow and Garder, 1993). This causes a satellite zenith angle dependence in the detection of high clouds. As the slant path effect 


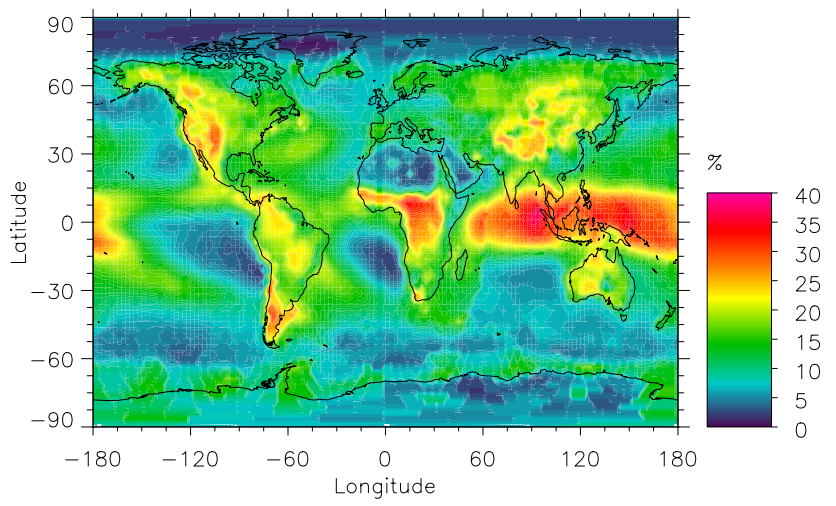

Fig. 1. Global map of average cirrus cover based on ISCCP VIS/IR data for the period 1984-1999 (in \% cloud cover).

of an optically thin cloud is larger than the nadir path effect, more thin cirrus is detected at slant views (as can be seen in the region pointed to above in the Indian Ocean). This feature is important when it comes to determining trends in cirrus, as will be discussed below.

\subsection{Trend estimation}

We have determined temporal trends in the ISCCP dataset. Trends have been established in two different ways. First, the dataset was divided into two 8 year periods, 1984-1991 and 1992-1999. Trends were taken as the difference between the two periods (in \% cloud cover/yr). Results are shown in Fig. 2a.

The satellite zenith angle dependence in the detection of cirrus described in the previous section suggests that great care must be taken when patterns in derived trends are to be studied. This effect, combined with the changing satellite positions and numbers of satellites operating over the years, produces spatial discontinuities in trends in cloud amount, even more clearly than what is the case in the data for cloud amount itself. Essentially they result from a change over the years in the viewing angle for each location. This puts a constraint on the use of trends from ISCCP, especially in investigations of geographical patterns. However, information on satellite viewing geometry and identity are provided in the ISCCP dataset, helping reduce and overcome the problems raised above.

To reduce the problems we have focused our trend analysis on regions which are covered by only one satellite each in the ISCCP data. A particular emphasis has been on the METEOSAT region. METEOSAT has not moved in the whole period of record, so that drifts in the zenith angle dependence are avoided. In the METOSAT region the strongest positive trends are found over central Africa. It is important to notice that there are large areas with negative trends.

Second, trends were established from linear regression of the yearly mean data in the 16 years period. Figure $2 \mathrm{~b}$ shows

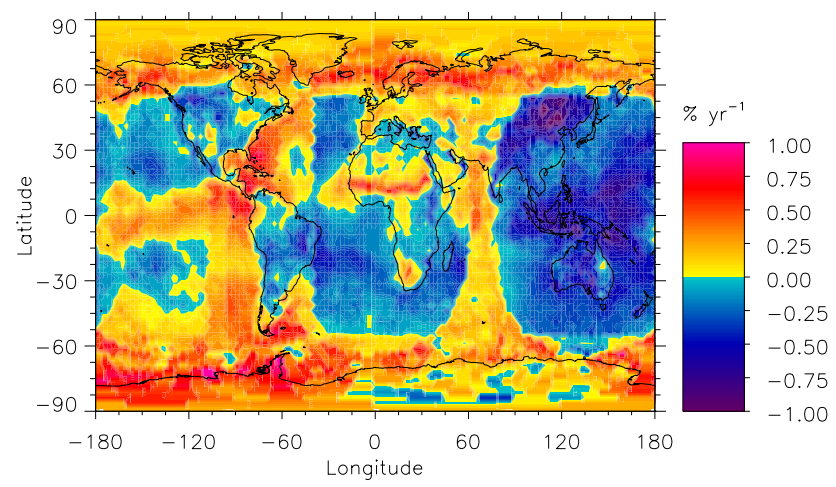

Fig. 2a. Changes in cirrus from ISCCP VIS/IR based on differences between the two periods 1992-1999 and 1984-1991 (in \% cloud cover per year).

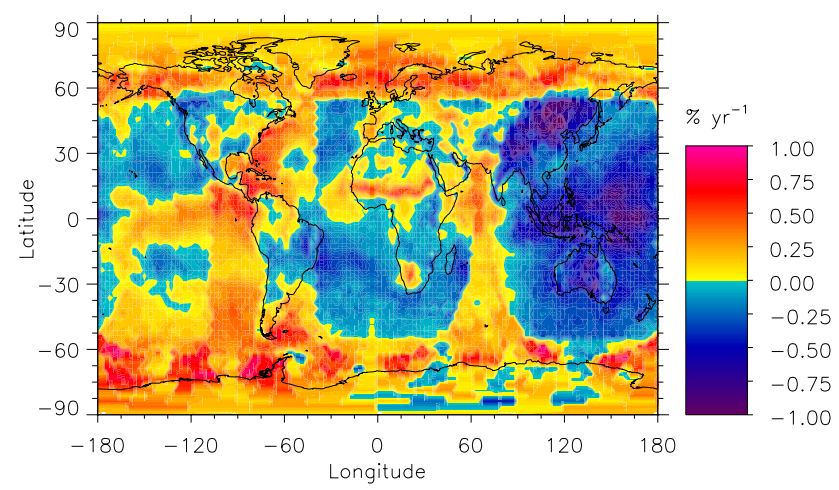

Fig. 2b. Changes in cirrus from ISCCP VIS/IR based on linear regression (in \% cloud cover per year).

that the trends derived from linear temporal regression are similar to those derived from the differences between the latter and the former years of cirrus, although some differences have been found. Both trends are used in the following.

The uncertainty in the estimated trends has been quantified in terms of the $95 \%$ confidence interval. The results are shown in Fig. 3 for the two methods. There is a substantial spatial variability in the confidence interval. However, the interval is relatively small in the METEOSAT region. Finally, the confidence intervals calculated for the two different trend estimating methods are rather similar, though with generally smaller intervals for the regression method. In general the confidence intervals for the two trends overlap.

In order to avoid the problems related to the satellite zenith angle dependence in the cloud detection in combination with the use of several satellites in ISCCP, we have selected 10 different regions for further investigation that are covered by only one single satellite (shown in Fig. 4). The trends in cirrus as seen in the ISCCP VIS/IR dataset (Fig. 2) in the METEOSAT region reveal a pattern with a general tendency of larger trends over land than over ocean in the European 


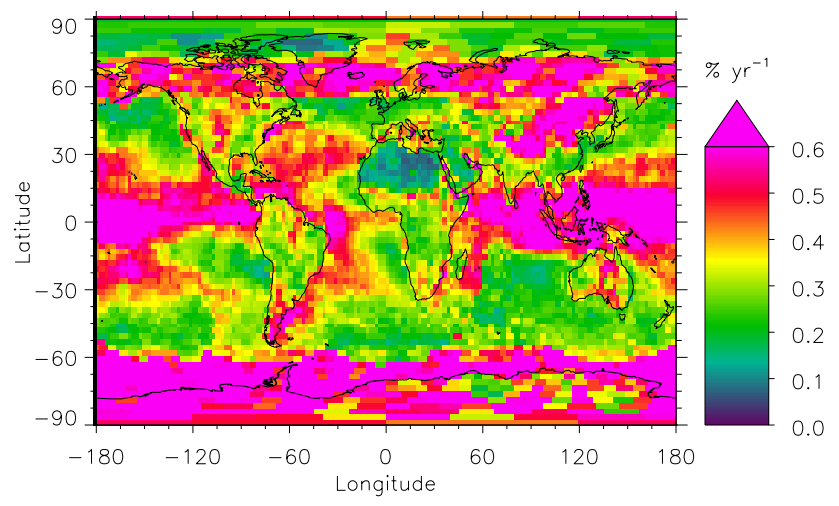

Fig. 3a. Confidence interval $(95 \%)$ in the calculation of changes in cirrus from ISCCP VIS/IR based on differences between the two periods 1992-1999 and 1984-1991 (in \% cloud cover per year).

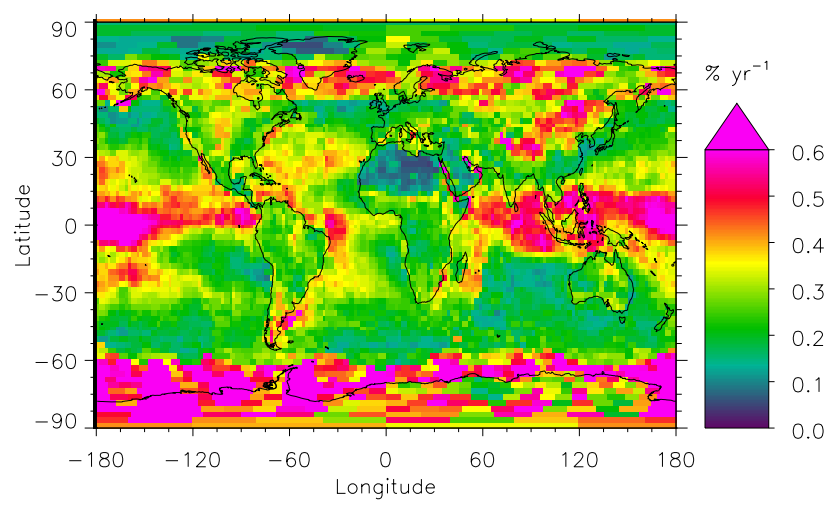

Fig. 3b. Confidence interval (95\%) in the calculation of changes in cirrus from ISCCP VIS/IR based on linear regression (in \% cloud cover per year).

sector. Changes in cloud cover in this region could be due to aircraft activity, but certainly also to high natural variability in this region. They could possibly also be caused by a climate change over the period of investigation. The large changes in cirrus cloud cover over Africa are certainly not due to aircraft. A few recent studies have pointed out that changes in anthropogenic aerosol emissions could have affected cloud cover in this region (Rotstayn and Lohmann, 2002; Kristjansson, 2002). To reduce the impact of phenomena other than aircraft, we have selected the 10 regions of further investigation so that they broadly cover either land or ocean areas.

\section{Aircraft impact on cirrus cover}

In this section we correlate the estimated trends in cirrus with aircraft flight data with the aim to quantify the impact of aircraft on the cirrus coverage.

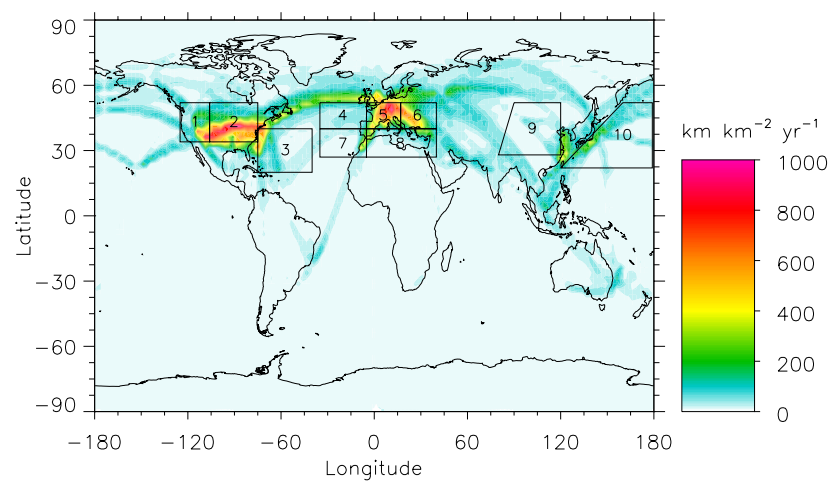

Fig. 4. Global map of distance flown with aircraft $\left(\mathrm{km} \mathrm{km}^{-2} \mathrm{yr}^{-1}\right)$ in year 2000 in altitude layer 17-19 (9760-11 $590 \mathrm{~m}$ altitude). Also shown are 10 regions used for trend analysis.

\subsection{Aircraft data}

Global fuel usage, $\mathrm{NO}_{\mathrm{x}}$ emissions and kilometres travelled were determined within the TRADEOFF project for the years 1992 and 2000 using the FAST model. FAST calculates inventories of fuel consumption, $\mathrm{NO}_{\mathrm{x}}$ emissions and distance travelled on a global grid, which is variable in horizontal and vertical dimensions as a user-specified input. For the TRADEOFF simulations, the inventories were generated at a vertical discretization of $610 \mathrm{~m}$, equivalent to one flight level.

The FAST model has its origins in the ANCAT/EC2 emissions inventory (Gardner et al., 1997, 1998) and uses the same movement database for 1991/92. Aircraft were modelled using 16 representative types and engine fuel-flow data for these 16 types were modelled using the PIANO aircraft performance model (Simos, 2003). Unlike previous inventories, the distance travelled per grid cell was also calculated for the months of January, April, July and October. The variation in total global distance is rather small compared with the average, with a maximum variation of approximately $3 \%$. The regional differences are, however, larger. The total distance travelled by civil traffic in 1991/92 was $17.4 \times 10^{9} \mathrm{~km} \mathrm{yr}^{-1}$.

In order to determine fuel, emissions and distance for 2000 , the model was used in forecast mode, in which the fleet was grown by statistics of Revenue Passenger Kilometres (RPK, a measure of fleet capacity used for inventory growth calculations). Scenario data underlying the IPCC (1999) emission projections were used but it was first necessary to determine which growth rate (IS92a, e or c) was appropriate for the period 1992 to 2000. ICAO RPK data were compared with the IPCC RPK scenario data and the actual growth rate between 1992 and 2000 was stronger than that suggested by the IS92e scenario. Thus, the "e" projection was utilized resulting in a global distance travelled of $25.1 \times 10^{9} \mathrm{~km} \mathrm{yr}^{-1}$. The distance travelled is non-linear with fuel; the fuel consumption increase estimated over the period 

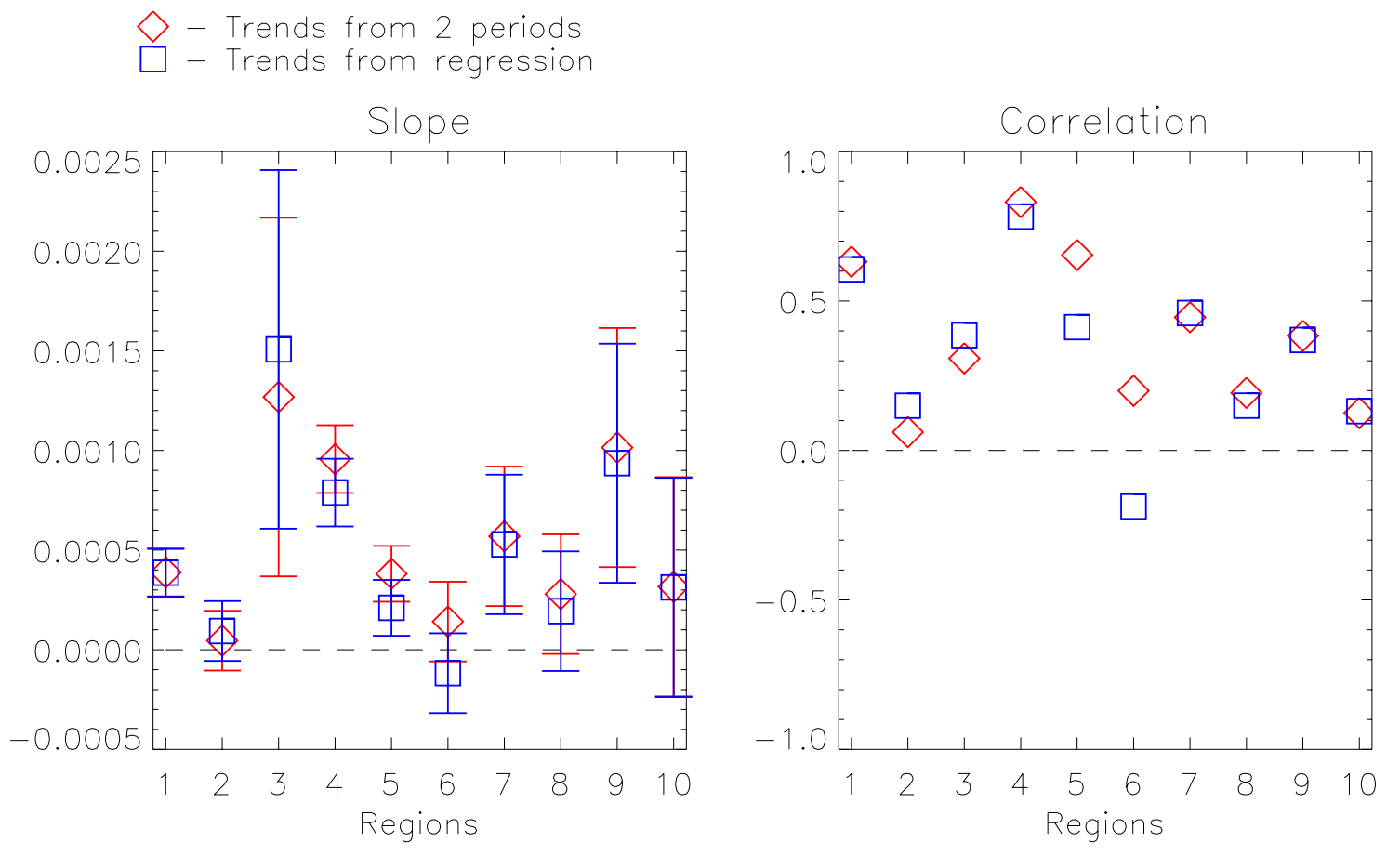

Fig. 5. Results of spatial regression analysis between trends in cirrus cloud amount from ISCCP VIS/IR and aircraft traffic density, for the slope in $\left(\% \mathrm{yr}^{-1}\right) /\left(\mathrm{km} \mathrm{km}^{-2} \mathrm{yr}^{-1}\right)$ and the correlation coefficient. Temporal trends have been determined from differences between two 8 year periods, and from linear regression, and traffic data are taken from the region encompassing layers 17-19 (9760-11 590 m altitude).

was $33 \%$, whereas the increase in total distance was approximately $44 \%$.

The distance flown is believed to be the parameter that most closely relates to the ability of aircraft to form contrails that later can develop into cirrus clouds, given that the environment is suitable for forming contrails. This parameter is thus used in the following analysis. Figure 4 shows a global map of the area density of the distance flown $(\mathrm{km}$ $\mathrm{km}^{-2} \mathrm{yr}^{-1}$ ) at an altitude favourable of contrail and cirrus formation, taken to be the region 9760-11590 m (layer 1719).

\subsection{Correlation between cirrus trends and aircraft data}

Our basic assumption is that a change in the area covered by cirrus in a region $\left(\mathrm{d} A\right.$, in $\left.\mathrm{km}^{2}\right)$ is proportional (factor $b$ ) to the change in aircraft flight distance $\left(\mathrm{d} L\right.$, in $\left.\mathrm{km} \mathrm{yr}^{-1}\right)$ over a unit of time:

$\mathrm{d} A=b \mathrm{~d} L$.

We integrate this equation over the 16 years of our investigation (beginning of 1984 to end of 1999 or beginning of 2000), and divide by the length of the time period ( $\Delta t=16 \mathrm{yr}$ ) to introduce the trend in cirrus as a convenient quantity. Next we introduce the factor $f=\left(L_{2000}-L_{1984}\right) / L_{2000}$ and arrive at the equation

$\left(A_{2000}-A_{1984}\right) / \Delta t=c L_{2000}$, where the constant

$c=b f / \Delta t$.

We have spatially correlated trends in cirrus with aircraft flight data within each of the $2.5^{\circ} \times 2.5^{\circ}$ grid cells in each of the 10 regions. Rather than using Eq. (2) directly we have used data for the area densities of $A$ (multiplied by 100) and $L$, denoted as $C$ (\% cloud fraction) and $D\left(\mathrm{~km} \mathrm{~km}^{-2} \mathrm{yr}^{-1}\right)$, respectively:

$\left(C_{2000}-C_{1984}\right) / \Delta t=100 c D_{2000}$.

To eliminate natural fluctuation in areas with very little aircraft activity we have introduced a cut-off limit for aircraft density, below which we exclude the data from the analysis. The results for the correlation coefficients and the slopes $100 c$ are shown in Fig. 5, with slightly different results for the two different methods to determine the cirrus trends. The results are shown for the layer 9760-11590m (layer 1719). The $95 \%$ confidence interval for the spatial regression is shown in the figure. Regressions have been tested for individual $610 \mathrm{~m}$ layers in the region above $8540 \mathrm{~m}$ and below $11590 \mathrm{~m}$, which encompasses the altitude range of the cruise level of most commercial flights, with very similar results. We have also tested various cut-off levels (a factor 5 higher and 2 lower than our standard value of $30 \mathrm{~km} \mathrm{~km}^{-2}$ ), again with rather similar results. 
Table 1. Global cirrus cover ( $\%$ cloud cover) due to aircraft in year 2000 , deduced from spatial correlation of trends in cirrus and aircraft traffic data.

\begin{tabular}{lccc}
\hline Regions included & Lower limit & Best estimate & Upper limit \\
\hline All 10 regions & 0.07 & 0.24 & 0.41 \\
METEOSAT regions & 0.10 & 0.23 & 0.38 \\
\hline
\end{tabular}

Correlation coefficients around 0.5 are found in region no. 1 (western US), no. 4 (part of the North Atlantic Flight Corridor) and no. 5 (western Europe). These regions have in common a generally high aircraft density, also with some contrasting areas with lower traffic density. In the regions east of two of the regions discussed above (area no. 2, eastern US, and area no. 6, eastern Europe and part of Asia) the correlation is weak. One possible explanation is advection (as discussed by Minnis et al., 2004). For example some of the cirrus resulting from air traffic in areas no. 1 and 5 could be advected, predominantly eastward, into the neighbouring regions no. 2 and 6, thus confusing any spatial relationship between the traffic there and cirrus induced locally by aircraft.

\subsection{Extrapolation to global scale}

Based on the results presented in the previous section, the correlation between trends in cloud amount and aircraft traffic suggests that aircraft may have influenced cirrus. The correlations with aircraft density are above 0.5 in certain regions. In order to declare an undisputed relationship between cirrus and air traffic, one would need to have a higher correlation coefficient. However, natural variability in cirrus clouds would mask such a relationship and weaken the correlation. We regard the results that we have found to be indicative of an impact of aircraft on cirrus amount as there are significant positive slopes in many regions with high aircraft density.

In order to assess the potential global impact of aircraft on cirrus formation we extrapolate the above results to a global scale. Based on the results presented above this can only be done in a relatively crude manner. We estimate the impact of aircraft on cirrus formation by estimating increases in cirrus areas in each of the 10 regions, adding the contributions and dividing by the area of the Earth's surface ( $a$ ), after integration of Eq. (1) from the time when aircraft traffic started until year 2000:

$$
\sum 100\left(\mathrm{~A}_{2000}-\mathrm{A}_{0}\right) / a=100 b / a \quad \sum L_{2000} .
$$

The left hand side of this equation equals the increase in \% cloud cover due to all aircraft in year 2000.

Notice that we need to scale the slope $100 c$ from the spatial regression according to Eq. (3) to find the constant $b$ used in Eq. (5). The scaling factor includes $f$ which is the increase in aircraft distance in the 16 year period of ISCCP investigation relative to aircraft distance in 2000. When using Eq. (5) to derive a global impact of aircraft on cirrus, we make a crude assumption that $f$ is geographically constant, i.e. the evolution of aircraft traffic has been similar throughout the world. This is of course a simplification. As we only have aircraft data for 1991/1992 and 2000 we also need to make an assumption on the evolution from 1984 to 1991/1992. Assuming that the data for 1991/1992 are valid for the middle point of the 16 year period of investigation, we estimate $f^{-1}=1.63$ in case of a linear evolution of aircraft since 1984, and $f^{-1}=1.93$ in case of an exponential evolution. In our analysis we use the lower value to be conservative in our estimates of aircraft induced cirrus.

To derive a global estimate, we need to include all parts of the world in solving Eq. (5). We have only made correlations between cirrus and aircraft in 10 regions. They cover 56\% of the global aircraft traffic. To arrive at a global estimate, we have scaled our results from Eq. (5) in the 10 regions by $1 / 0.56$, assuming thus that the cirrus-aviation relation is similar to the aircraft-traffic weighted average of the 10 regions outside those regions. The results are summarized in Table 1.

As our derived cirrus trends in the METEOSAT region are considered to be least uncertain we have also used the subset of regions in the METOSAT in an additional global estimation. In this case we cover $21 \%$ of the global aircraft traffic, and we scale our result to global scale accordingly. These results are also included in Table 1, where also lower and upper limits according to the $95 \%$ confidence interval are given. In both cases we have found with $95 \%$ certainty that aircraft have induced a positive change in global cirrus cover. As expected the confidence interval is slightly narrower in the case where only data from the METEOSAT region were used, but both in the mean and in the lower and upper limits the two approaches (METEOSAT regions vs. all 10 regions) yield rather similar results.

Our global estimates in Table 1 are a result of spatial correlations adopting cirrus trends from the two different methods. The numbers in Table 1 are based on averages of slopes $100 c$ and confidence intervals derived in the two cases. In the METOSAT case the ratio of the mean values derived from the two trend methods is 1.6 , in the global case this ratio is only 1.1 .

The confidence intervals discussed in the previous paragraph (and given in Table 1) result from the spatial correlation of cirrus change and aircraft traffic data only. The trend value used was the best estimate. The uncertainty in trends was not considered. We have found that the uncertainties in trends will induce a broader confidence interval (for the spatial correlation with aircraft) only if we assume that the trends are towards the lower end of the uncertainty range in areas of high aircraft traffic and towards the higher end in areas of little traffic. This is not a likely situation, as we have chosen regions of investigation in relatively homogeneous regions (as discussed above). Simply assuming that all trends 
Table 2. Radiative forcing $\left(\mathrm{Wm}^{-2}\right)$ due to aircraft induced cirrus (year 2000), adopting the global cirrus cover derived from the METEOSAT regions (in Table 1).

\begin{tabular}{lccc}
\hline $\begin{array}{l}\text { Adopted radiative impact of cirrus } \\
\left(\mathrm{Wm}^{-2} \text { per } 1 \% \text { cloud cover) }\right.\end{array}$ & Lower limit & Best estimate & Upper limit \\
\hline $\begin{array}{l}0.06 \text { (Marquart et al., 2003) } \\
0.12 \text { (Myhre and Stordal, 2001) }\end{array}$ & 0.01 & & \\
0.20 (Boucher, 1999) & & 0.03 & 0.08 \\
\hline
\end{tabular}

in each region equals the low or the high estimate has a rather modest impact on the results for the slopes in the spatial regression (estimated to be within about $10 \%$ relative).

Europe is the area within the region covered by METEOSAT which has the highest aircraft density. We have used the two European regions (no. 5 and 6) to estimate the change in cirrus due to aircraft by adopting Eq. (4). We found a trend in cirrus due to aircraft of $1-2 \% /$ decade (note that this is in absolute $\%$ point units for cirrus cloud coverage; $1 \%$ is the average for the two regions in the case of trends based on two time periods, $2 \%$ from trends based on temporal regression). The amount of cirrus that we have attributed to aircraft traffic in Europe is 3-5\% cloud cover, approaching half of the present cirrus amount. Our results are similar to those derived for Europe by Zerefos et al. (2003), who also based their analysis on the same ISCCP data, but used a different statistical approach. Zerefos et al. (2003) found an increase in cirrus cover in high air traffic areas of Europe of $+1.3 \%$ /decade, contrasted by a decrease of $0.2 \%$ /decade in low air traffic areas, which can be interpreted as a $1.5 \% / y r$ trend in cirrus due to aircraft. Boucher (1999) found a somewhat stronger increase in cirrus, almost 3\%/decade, over continental regions with high aircraft traffic, resulting from an even stronger trend in occurrence of cirrus but correcting for a negative trend in cirrus "amount when present". Zerefos et al. (2003) also included an analysis of trends in the North Atlantic Flight Corridor (NAFC), but their results are probably less reliable in this case as their area of investigation was based on trends in cirrus derived from several satellites.

Downward trends in cirrus in low traffic regions found in Zerefos et al. (2003) and in this work are consistent with a general decrease in upper level clouds which was found over mid-latitude continental regions in the Northern Hemisphere by Norris et al. (2005).

\section{Climate impact of aircraft induced cirrus}

To find the radiative forcing we multiply the global aircraft induced cirrus cover calculated in the previous section with the radiative impact of cirrus. We combine the mean estimate of change in cirrus with a mid range value of $0.12 \mathrm{Wm}^{-2}$ per $1 \%$ cloud cover (see e.g. Myhre and Stordal, 2001, and ref- erences therein, assuming that the radiative forcing change is the same per unit of cloud cover for aircraft induced cirrus and contrails). We then arrive at a global mean radiative forcing change due to an aircraft effect on cirrus that is $0.03 \mathrm{Wm}^{-2}$. We have here used a radiative impact of contrails for aircraft induced cirrus which is likely lower than the one for cirrus on a global scale, as cirrus in the tropics have a larger LW radiative effect. To explore the range of radiative forcing we have used also two other estimates for radiative impact of cirrus, namely a lower one, $0.06 \mathrm{Wm}^{-2}$ per $1 \%$ cloud cover, by Marquart et al. (2003), and a higher one, $0.20 \mathrm{Wm}^{-2}$ per $1 \%$ cloud cover, from Boucher (1999). We have combined the low and high values, respectively, with the lower and higher estimates of changes in aviation induced cirrus (using the numbers based on the METEOSAT region in Table 1). The lower and upper limits are estimated to 0.01 and $0.08 \mathrm{Wm}^{-2}$, respectively (see Table 2 ).

\section{Conclusions}

In this study we have found indications that cirrus cloud amount increases have accompanied an increase in air traffic in the 16 year period 1984-1999 contrasting with a general negative trend. However, the relationship between cirrus cloud amount and aircraft density is uncertain and we cannot draw firm conclusions or quantify the effect with high certainty. We find that the strongest influence on cirrus clouds, as manifested in the ISCCP VIS/IR dataset, occurs in parts of the regions with the highest aircraft traffic. Our results may still be influenced by natural variability, climate change, and other anthropogenic impacts.

Our mean estimate of the radiative forcing $\left(0.03 \mathrm{Wm}^{-2}\right)$ is close to the number given in the IPCC (1999) (upper limit in their assessment is $0.04 \mathrm{Wm}^{-2}$ ), and rather similar to the upper limit estimated by Minnis et al. (2004), for the total effect of cirrus and contrails, of $0.026 \mathrm{Wm}^{-2}$ in the mid $1990 \mathrm{~s}$. It is significant compared to the total radiative forcing due to aircraft from all effects other than cirrus, which was estimated to be $0.1 \mathrm{Wm}^{-2}$ (IPCC, 1999).

In conclusion there are indications that cirrus cloud cover increased over the last two decades of the previous century in regions with high aircraft traffic, contrasting with a general 
decrease in cirrus for other reasons. From our results we conclude that cirrus from aircraft can potentially contribute to global warming over the last few decades. However, the correlations between cirrus change and aircraft traffic are only moderate, as many other factors may also have contributed to changes in cirrus over the same time period. To improve the results based on the method adopted in this paper one could use daily data rather than monthly means, and also make an attempt to take into account advection of aircraft induced cirrus.

Acknowledgements. This work was supported by the EU funded project TRADEOFF and by the NASA REASON program. We thank K. Shine and R. Sausen for valuable discussions.

Edited by: U. Lohmann

\section{References}

Boucher, O.:Air traffic may increase cirrus cloudiness, Nature, 397, 30-31, 1999.

Chagnon, S. A.: Midwestern cloud, sunshine and temperature trends since 1901 - Possible evidence of jet contrail effects, J. Appl. Meteorol., 20, 496-508, 1981.

Chen, T., Rossow, W. B., Zhang, and Y-C.: Radiative effects of cloud-type variations, J. Climate, 13, 264-286, 2000.

Duda, P. D., Minnis, P., Nguyen, L., and Palikonda, R.: A case study of the development of contrail clusters over the Great lakes, J. Atmos. Sci., 61, 1132-1146, 2004.

Gardner, R. M., Adams, K., Cook, T., Ernedal, S., Falk, R., Fleuti, E., Herms, E., Johnson, C. E., Lecht, M., Lee, D. S., Leech, M., Lister, D., Massé, B., Metcalfe, M., Newton, P., Schmitt, A., Vandenbergh, C., and van Drimmelen, R.: The ANCAT/EC global inventory of $\mathrm{NO}_{\mathrm{x}}$ emissions from aircraft, Atmospheric Environment, 31, 1751-1766, 1997.

Gardner, R. M. (Ed.): ANCAT/EC2 aircraft emissions inventories for 1991/92 and 2015: Final Report.EUR-18179, ANCAT/EC Working Group, 84 pp. plus appendices, ISBN-92-828-2914-6, 1998.

IPCC: Aviation and the Global Atmosphere, A Special Report of IPCC (Intergovernmental Panel on Climate Change), edited by: Penner, J. E., Lister, D. H., Griggs, D. J., Dokken, D. J., and McFarland, M., Cambridge University Press, Cambridge, UK, 373 pp., 1999.

IPCC: Intergovernmental Panel on Climate Change 2001: The Scientific Basis, edited by: Houghton, J. T., Ding, Y., Griggs, D. J., Noguer, M., van der Linden, P. J., Dai, X., Maskell, K., and Johnson, C. A., Cambridge University Press, Cambridge, UK, 881 pp., 2001.

Jin, Y., Rossow, W. B., and Wylie, D. P.: Comparison of the climatologies of high-level clouds from HIRS and ISCCP, J. Climate, 9, 2850-2879, 1996.

Kristjansson J. E.: Studies of the aerosol indirect effect of sulphate and black carbon aerosols, J. Geophys. Res., 107, No. D15, doi:10.1029/2001JD000887, 2002.
Liao, X., Rossow, W. B., and Rind, D.: Comparison between SAGE II and ISCCP high-level clouds, Part I: Global and zonal mean cloud amounts, J. Geophys. Res., 100, 1121-1135, 1995.

Machta, L. and Carpenter, T.: Trends in high cloudiness in Denver and Salt Lake City, in: Man's Impact on Climate, edited by: Matthews, W. H., Kellogg, W. W., and Robinson, G. D., MIT Press, Cambridge, Massachusetts, and London, England, 1971.

Marquart, S., Ponater, M., Mager, F., and Sausen, R.: Future Development of Conrail Cover, Optical Depth, and Radiative Forcing: Impacts of Increasing Air Traffic and Climate Change. J. Climate, 16, 2890-2904, 2003.

Minnis, P., Young, D. F., Garber, D. P., Nguyen, L., Smith jr., W. L., and Palikonda, R.: Transformation of contrails into cirrus during SUCCESS, Geophys. Res. Lett., 25, 1157-1160, 1998.

Minnis, P., Schumann, U., Doelling, D. R., Gierens, K. M., and Fahey, D. W.: Global distribution of contrail radiative forcing, Geophys. Res. Lett., 26, 1853-1856, 1999.

Minnis, P., Kirk Ayers, J., Palikonda, R., and Phan, D.: Contrails, Cirrus Trends, and Climate, J. Climate, 17, 1671-1685, 2004.

Myhre, G. and Stordal, F.: On the tradeoff of the solar and thermal infrared radiative impact of contrails, Geophys. Res. Lett., 28, 3119-3122, 2001.

Norris, J. R.: Multidecadal changes in near-global cloud cover and estimated cloud cover radiative forcing, J. Geophys. Res., 110, doi:10.1029/2004JD005600, 2005.

Ponater, M., Marquart, S., and Sausen, R.: Contrails in a comprehensive global climate model: Parametrization and radiative forcing results, J. Geophys. Res.,107, doi:10.1029/2001JD000429, 2002.

Rossow, W. B. and Garder, L. C.: Cloud detection using satellite measurements of infrared and visible radiances for ISCCP, J. Climate, 6, 2341-2369, 1993.

Rossow, W. B. and Schiffer, R. A.: ISCCP Cloud data products, Bull. Amer. Meteor. Soc., 72, 2-20, 1991.

Rossow, W. B. and Schiffer, R. A.: Advances in understanding clouds from ISCCP, Bull. Amer. Meteor. Soc., 80, 2261-2287, 1999.

Rotstayn, L. D. and Lohmann, U.: Tropical rainfall trends and the indirect aerosol effect, J. Climate, 15, 2103-2116, 2002.

Schiffer, R. A. and Rossow, W. B.: ISCCP global radiance data set: A new resource for climate research, Bull. Amer. Meteor. Soc., 66, 1498-1505, 1985.

Simos: PIANO Project Interactive Analysis and Optimisation aircraft performance tool, http://www.lissys.demon.co.uk, 2003.

Stubenrauch, C. J., Rossow, W. B., Cheruy, F., Chedin, A., and Scott, N. A.: Clouds as seen by satellite sounders (3I) and imagers (ISCCP). Part 1: Evaluation of cloud parameters, J. Climate, 12, 2189-2213, 1999.

Travis, D. J., Carleton, A. M., Lauritsen, R. G., Contrails reduce daily temperature range, Nature, 418, 601, 2002.

Zerefos, C. S., Eleftheratos, K., Balis, D. S., Zanis, P., Tselioudis, G., and Meleti, C.: Evidence of impact of aviation on cirrus cloud formation, Atmos. Chem. Phys., 3, 1633-1644, 2003,

SRef-ID: 1680-7324/acp/2003-3-1633. 